\title{
Enhancing academic engagement in knowledge transfer activity in the UK
}

Dr. Jan Francis-Smythe

BSc.(Hons).MSc.DipPsych.C.Psychol.AFBPsS

Chartered Occupational Psychologist

Director of Centre for People @ Work

Business School

University of Worcester

Henwick Road

Worcester

WR2 6AJ

Tel: 01905855242

Fax: 01905855439

j.francis-smythe@worc.ac.uk

(c) Centre for People @ Work

Dr. Jan Francis-Smythe is Director of the Centre for People @ Work, a research and consultancy centre, based in the Business School at University of Worcester. She is a Chartered Occupational Psychologist and has previously been Director of the Enterprise Unit and Head of Psychology at Worcester. She has a PhD from UMIST and MSc from the University of Bristol. Her main research interest is time in organisations. She is an Associate Fellow of the British Psychological Society. Address for correspondence: Dr. Jan Francis-Smythe, Centre for People @ Work, Worcester Business School, University of Worcester, Henwick Grove, Worcester WR2 6AJ. Tel: 01905 855242; Email: j.francis-smythe@worc.ac.uk. 


\section{Enhancing academic engagement in knowledge transfer activity in the UK}

\section{Introduction}

There has been an increasing call in the UK over the last decade for universities to become more entrepreneurial with a strengthening of university and industry/community links to contribute more significantly to the knowledge economy ('The Future of Higher Education' (January, 2003), the Lambert Review of Business-University collaboration (December 2003), the Higher Education Funding Council's HEIF (Higher Education Innovation Funding) 'third-stream' initiatives (from 1999) and the Sainsbury Review of Science and Innovation (October 2007)). This has prompted much debate about the changing focus of universities from traditional 'national and international pure and applied research' to 'local/regional applied research and consultancy' (Scott 2004, Rinnie and Koivula 2005, Shattock 2005) with this latter 'entrepreneurial' approach being proposed by some as destructive of traditional academic values (Ritzer 1999, Barnett 2003) whilst others see it more positively as compatible and indeed enabling (Shattock 2005, Crespo 2007).

Whilst admittedly, reviews such as Lambert have identified that there is more to be done on the 'demand' side (business) than the university, nevertheless this has heightened awareness of the need for all UK Higher Education Institutions (HEIs) to consider ways in which they can more actively engage in knowledge transfer (KT), whether it be from the application of research, the dissemination of expertise through consultancy or the transfer of best practice through CPD programmes.

Many institutions are now setting targets for engaging in 'third stream' KT activity, at institutional, departmental and individual levels, but the degree to which consideration has been given to the skills/competencies required by academics to do this and the barriers they may face has been limited. One empirical study of academics suggests that 'academics exhibit a strong commitment to engagement and interaction with their communities both in principle and practice, .....and that it is often accomplished under less than propitious circumstances' (Bond 2005:331). It is these circumstances that are the focus of this paper.

Whilst there are initiatives in place to support academics in activities aimed at securing commercial opportunities (such as licensing or seed/venture finance through, for example, the Research Councils Follow-On-Fund), this paper focuses on some primary research (funded by CONTACT Knowledge Exchange and carried out by the Centre for People @ Work at the University of Worcester), to establish firstly, the competencies academics require to 'enable' them to engage and secondly, the potential barriers they face. The objective of the research was to provide evidence-based information to help inform key HR processes in order to further facilitate the embedding of KT activity into UK HEIs.

Defining the role and the competencies required and putting in place mechanisms to help develop these competencies is obviously crucial to the task of promoting and enhancing academic engagement in KT. This research demonstrated the two primary competencies 
required were Presenting and Communicating Information and Relating \& Networking. Table 1 lists the top five competencies elicited from this study together with example behavioural indicators. (For a full report of this aspect of the study see Francis-Smythe \& Haase, 2007 (under review).)

A review of the KT literature gave some suggestions of possible barriers. These fell into essentially two categories: individual (individual behaviours- Yih-Tong and Scott 2005) and institutional (culture, time frames and language - Crosswaite and Curtice 1994, organizational characteristics- Jacobson et al 2005). The latter suggests characteristics of universities make knowledge transfer a difficult undertaking:

The structure of academia is such that members of the academy, individually and collectively, are largely accountable to their disciplines; ideas for new research therefore must be situated in the questions and methods of the discipline. Legitimacy is obtained through peer review of process and product. Rewards and incentives like tenure and promotion are dependent on meeting disciplinary standards. Thus, for consulting to be more widely embraced, academia must change some of its own structures and practices. Jacobson, et al. (2005:317)

This paper reports the findings of the 'barriers' aspect of the research study.

\section{Method}

The study used both focus groups and an on-line survey. The focus groups were carried out first in order to elicit views and opinions which were then tested out on a larger sample through the survey. Three groups of individuals with different degrees of involvement in KT activities in an HEI context were involved: 1) Knowledge Transfer Professionals (KTPs), e.g. KT staff in Regional Offices, Business Development Managers etc.; 2) Academics with a full or part-time dedicated KT role e.g. Medici or Innovation fellows and 3) Academics who engage in KT as part of their normal academic contract. KTPs were included as they work very closely with academics and would thus have views on the perceived barriers they face.

In order to maximize response rate, the institutional KT representative in each of thirteen West Midlands HEIs nominated people under each category for the research. As a result sixty-seven KT specialists, forty-one academics with a dedicated KT role and forty-seven academics without a dedicated KT role, were approached by Email and invited to participate at their preference either in a focus group or on-line survey. Overall, thirtytwo, ten and fourteen responses were received respectively, representing response rates of $48 \%$, $24 \%$ and $30 \%$ (overall of $39 \%$ ).

\section{Stage 1 - Focus groups}

Forty-five people took part in six focus groups held in three different regional locations in February 2006. An open brain-storming approach was used to elicit the barriers. Participants were asked to name and describe barriers that they had experienced or which they had found to impede an academic’s involvement in KT. 


\section{Stage 2 - Online survey}

The survey was carried out between April and May 2006 and sixty anonymised responses were received. Individuals from seven higher education institutions participated in the survey, thirty were KT professionals, twenty-two were academics without a dedicated KT role and eight were academics with a dedicated KT role.

Respondents were invited to rate the barriers elicited through the focus groups as to the extent to which they felt they would impede on an academic's engagement in KT (1=very little to $5=$ =very great).

\section{Results}

A total of nineteen institutional (see table 2) and twenty individual (see table 3) barriers were identified ranging from rewards and incentives through to risk aversion. For each barrier a mean score rating of how significant the barrier was perceived to be (5=high) and a measure of the spread of the responses (S.D. standard deviation) is given. The variation of responses within each barrier (individual and institutional) is relatively consistent ( $\mathrm{SD}=0.9$ to 1.3 ) suggesting that overall there was much agreement on the ratings. There is greater variation between the mean significance ratings of the individual barriers than the institutional ones (4.05-2.2 vs. 3.63-2.68 resp.) showing that respondents were able to differentiate more easily between the importance of the individual barriers than the institutional ones.

Insert table 2 about here

Insert table 3 about here

Three institutional and four individual barriers ranked relatively higher than the rest thus standing out as the key perceived barriers. The top three institutional ones were: lack of reward/incentives for department, lack of investment in core academic/research KT staffing (i.e. mostly project-based), bureaucracy (form-filling) required to engage in KT processes. The top four individual ones were: academic's time available to pursue KT is too fragmented, lack of academic's time to engage in KT, lack of reward/incentives for academic, mis-match of academic and commercial time-scales.

Interestingly, lack of reward/incentives appears in the top three at both the institutional and individual level. Whilst it has generally been acknowledged for some time that reward and recognition at an individual level is important, this study shows that it is also important at department level. Departments know the rewards of bringing in more students and research funding, but what are they for KT? Often there is even no reinvestment in KT departmental resourcing leading to the second top institutional barrier: The lack of investment in core KT staffing. This has its effect on inability to be proactive, to respond to leads and to role overload on those who are 'left to pick up the pieces'. With few rewards/incentives, little investment in KT core staffing, bureaucratic formfilling then often becomes the 'final straw'.

Of most interest is the finding that at the individual level, three of the top four barriers relate to time. Most importantly, it is not lack of time per se that is the biggest barrier, but 
lack of suitable blocks of time in which to carry out the work. This might suggest that expecting academics to engage in all four activities of teaching, research and administration and KT is simply too much. The degree of multi-tasking or polychronicity that this requires is problematic when one considers the complex and often conceptual nature of the tasks involved. A study by Frei et al (1999) showed that whilst academic faculty members' involvement in multiple projects gave the impression they were polychronic, they had a preference for monochronicity. Requiring polychronic behaviour from people with monochronic tendencies is likely to result in either or both poorer performance and psychological well-being. Lack of time itself is still perceived as a major barrier. King (2004) showed lack of time time as the principle barrier to academics engaging in CPD. If we also identify that academics need additional training /CPD to engage in KT, time will become even more of a limiting factor. The 'mis-match of time scales' barrier may be due to the fact that clients working with commercial experts are able to expect the expert to dedicate themselves totally to a project once it has started whereas with most academics KT projects are run alongside their other tasks and as such have to take place over an extended period of time. It must be acknowledged however, that the 'mis-match of time scales' barrier was also perceived by some participants as a lack, by academics, of a sense of urgency or a need for adherence to deadlines.

The results also demonstrate that there are significant differences especially between KTPs and academics with regard to the perception of the importance of certain barriers. KTPs appear to perceive academics 'lack of motivation to engage in KT activities', 'their personal preference for UG/PG teaching/pure research' as well as the fact that KT was perceived as 'of less value than teaching and research' to impede stronger on academics' engagement in KT activities than academics do themselves. However, slight differences were also apparent between academics with and academics without dedicated $\mathrm{KT}$ roles. Compared to academics with a dedicated KT role, academics without a dedicated KT role felt that the lack of investment in up-to-date equipment would impede more on their engagement in KT. At the same time, they felt that their risk aversion was less of a barrier to engagement in KT activities than it was perceived by academics with a dedicated KT role. This information is important since it suggests that the different groups (KTPs, dedicated KT academics, standard contracted academics) perceive different barriers to be of importance. Typically, there might be barriers that academics do not actively perceive but that do in fact impede on their engagement (e.g. risk aversion). Addressing these barriers proactively, for instance, a general assessment of academics' risk aversion and how it might be overcome might increase the extent to which standard contacted academics can be encouraged to be involved.

Differences in perceived barriers between universities were also noted, typically, for some lack of reputation, for others mismatch client/academic needs, lack of mentors, mismatch academic and client timescales and unclear KT processes were more important. Clearly, different institutions may require different interventions.

Whilst this study focuses solely on the UK it should be noted that the EUEREK (European Universities for Entrepreneurship-their Role in the Europe of Knowledge) project has explored barriers to entrepreneurialism in universities across seven European 
nations and whilst the topic area is broader a number of the factors identified in this study are replicated there (http://www.euerek.info/Public Documents/General). Similarly, Shattock (2005:23) in discussing European universities 'identifies the importance of academic "intrapreneurs" and the need that structures and constraints need to be loosened to enable them to flourish'.

Despite efforts to maximize involvement the overall level of participation in the study was disappointing, most specifically with the focus groups and most particularly with academics, especially given the majority of these people had been nominated as 'willing' by their institutional KT representative. Whether this is simply due to a 'too many surveys fatigue', is more specifically related to the time barriers identified in this study, or is the result of a more general negative attitude towards KT as a result of the culmination of all of the barriers is not possible to tell.

\section{Conclusions}

Knowledge of the barriers makes it possible to begin to actively address them. This study suggests the key focus at institutional level should be by implementing systems to recognise and reward departments for KT, by including KT in staffing strategies and by adapting and reducing administrative systems to cope with the required flexibility of KT work. It also suggests at the individual level the key focus should be on appropriate workload planning to incorporate KT. This however needs to be sensitive to two main issues: time fragmentation and dilution of expertise/role breadth. Time fragmentation can be addressed by either compartmentalising KT time or by supporting/developing academics to behave more polychronically. Dilution of expertise/role breadth needs serious consideration. If the competencies required to carry out a broad range of activities such as teaching, research, administration and KT are different, and even sometimes competing, then individual performance and well-being may suffer.

The extent to which Human Resource (HR) processes in UK HEIs (e.g. job/role analysis, training/development provision, reward schemes) at national and local levels currently incorporate third-stream KT activity appears patchy and under-developed (for a review see Francis-Smythe and Haase (2006)). Where it has occurred, for example, Sunderland University, this has been through embedding 'third stream' activity into the culture, with the implementation of strategic and operational frameworks and support systems which better support, promote, develop, recognise and reward KT activity. Others have addressed the 'time' issue by focusing on allowing for dedicated KT time by a number of different routes. By way of example, Fellowship schemes exist (e.g. Medici in the Midlands, Liverpool John Moores, Aston, Bournemouth, Nottingham Trent and Worcester Universities) with varying degrees of support and training for appointed academics to increase their KT activity. Additionally, in 2006 the Higher Education Funding Council (HEFCE) embarked on a programme entitled 'Enhancing impact through good practice in knowledge transfer and exchange' which has sought to distil and share good practice in knowledge exchange. The programme aims to deliver generic transferable good practice models online and facilitate the development of communities of practice (see http://www.ktgoodpractice.org/). The extent to which yet more 
examples/recipes of 'good practice' in this area will come forward in the current good practice programme has yet to be determined, the fact that such a programme is urgently required is certainly supported by the findings of this study.

Whilst it needs to be acknowledged that the amount of direct UK governmental funding available for knowledge transfer is relatively small compared to teaching and research (Brown, 2004) it has been increased in the fourth round of HEIF (HEIF4) to $£ 150$ million. HEIF4 notably, reflecting Lord Sainsbury's report (October, 2007), places greater emphasis (double weighting within the external income component) on working with small and medium-sized enterprises (SMEs). Greater and more successful engagement with these types of organisations is likely to depend very much on our being able to increase the pool of 'engaged' academics. In this SME context this is likely to demand both exactly the type of competencies identified by this study (e.g. Presenting and Communicating Information, Relating \& Networking) and the removal of many of the barriers that are currently perceived to exist.

\section{References}

BARNETT, R. (2003) Beyond all reason. Living with ideology in the university, (Buckingham,SRHE and Open University Press).

BARTRAM,D. (2005). The great eight competencies: A criterion-centric approach to validation. Journal of Applied Psychology, 90, (6) 1185-1203.

BOND,R. \& PATERSON,L. Coming down from the ivory tower? Academics' civic and economic engagement with the community. Oxford Review of Education, 31, (3) 331351.

BROWN, R. (2004) The future structure of the sector: what price diversity? perspectives, 8, (4) 93-99.

CRESPO,M. (2007) Intensification of university-industry relationships and its impact on academic research. Higher Education, 54, (1) 61-84.

CROSSWAITE,C. \& CURTICE,L. (1994) Disseminating Research Results - The Challenge of Bridging the Gap between Health Research and Health Action. Health Promotion International 9, (4) 289-96.

DEPARTMENT FOR EDUCATION AND SKILLS, (2003) The future of higher education. Cm 5735 (London, The Stationery Office).

FRANCIS-SMYTHE, J. \& HAASE, S. (2006) Competencies and continuing professional development (CPD) for academics in knowledge exchange (KE) activity. Report prepared for the CONTACT Knowledge Exchange. November 2006. 
FRANCIS-SMYTHE.J. \& HAASE,S. (2007) Developing academics' competence in knowledge transfer (KT) activity (under review).

FREI RL, RACICOT B, TRAVAGLINE A. (1999) The impact of monochronic and Type A behavior patterns on research productivity and stress. Journal of Managerial Psychology, 14, (5) 374-387.

HIGHER EDUCATION FUNDING COUNCIL FOR ENGLAND (2007) Higher education innovation fund round 4 (Bristol, HEFCE, October 2007).

JACOBSON,N., BUTTERILL,D. \& GOERING,P. (2004) Organisational factors that influence university-based researchers' engagement in knowledge transfer activities. Science Communication, 25, (3) 246-259.

KING,H. (2004). Continuing Professional Development in Higher Education: what do academics do? Educational Developments, Dec.2004, Issue 5.4.

HM TREASURY (2003) Lambert review of business-university collaboration. Final Report. December 2003 (Norwich, HMSO).

HM TREASURY (2007) The race to the top. A review of government's science and innovation policies. Lord Sainsbury of Turville, October 2007 (Norwich, HMSO).

RINNIE,R. and KOIVULA,J. (2005) The changing place of the university and a clash of values. The entrepreneurial university in the European knowledge society. A review of the literature. Higher Education Management and Policy, 17, (3) 91-123.

RITZER,G. (1999) The McDonaldisation thesis. Explorations and extension, (London, SAGE Publications).

SCOTT,P. (2004) Ethical and moral dimensions for higher education and science in Europe. Ethics 'in' and 'for' higher education. Higher Education in Europe, XXIX, (4) 439-450.

SHATTOCK ,M.(2005) European Universities for Entrepreneurship: Their Role in Europe of Knowledge The Theoretical Context, 17, (3) 13-25.

YIH-TONG SUN,P. \& SCOTT,J.L. (2005). An investigation of barriers to knowledge transfer. Journal of Knowledge Management, 9, (2) 75-90. 
Table 1. Top five competencies required by academics for KT engagement

\begin{tabular}{|l|l|l|}
\hline Rank & Competency dimension & Examples of behavioural indicators \\
\hline 1 & $\begin{array}{l}\text { Presenting and } \\
\text { Information }\end{array}$ & $\begin{array}{l}\text { - Put information across concisely and } \\
\text { easily accessible for client } \\
\text { - Relate to audience and adapt to their } \\
\text { needs }\end{array}$ \\
\hline 2 & Relating \& Networking & $\begin{array}{l}\text { - Build rapport through regular contact } \\
\text { with client } \\
\text { - Network with other academics who are } \\
\text { involved in KT work }\end{array}$ \\
\hline 3 & $\begin{array}{l}\text { Delivering Results and } \\
\text { Eeeting Customer }\end{array}$ & $\begin{array}{l}\text { - Establish client's needs through probing } \\
\text { and confirm them in writing } \\
\text { - Manage expectations on both sides }\end{array}$ \\
\hline 4 & $\begin{array}{l}\text { Entrepreneurial \& } \\
\text { Commercial Thinking }\end{array}$ & $\begin{array}{l}\text { - Stay in touch with latest development } \\
\text { within the industry } \\
\text { - Identify and develop technology ahead } \\
\text { of the market and industry demand }\end{array}$ \\
\hline 5 & Planning \& Organising & $\begin{array}{l}\text { - Clarify outputs/deliverables } \\
\text { - Provide clear timetable }\end{array}$ \\
\hline
\end{tabular}

These competency dimension titles are based on the Great Eight (Bartram,2005) and taken from the SHL Universal Competency Framework ${ }^{\mathrm{TM}}$ Profiler and Designer cards (copyright (C) 2004 by SHL Group plc) with permission of the copyright holder. 
Table 2. Institutional barriers impeding on academics’ engagement in KT activities

\begin{tabular}{|l|r|r|}
\hline & \multicolumn{1}{|l|}{ Mean } & \multicolumn{1}{l|}{ S.D. } \\
\hline Lack of reward/incentives for Department & 3.63 & 1.21 \\
\hline $\begin{array}{l}\text { Lack of investment in core academic/research KT staffing (i.e. } \\
\text { mostly project-based) }\end{array}$ & 3.58 & 1.22 \\
\hline Bureaucracy (form-filling) required to engage in KT processes & 3.53 & 1.06 \\
\hline Difficulty in finding replacements for academics 'bought-out' & 3.40 & 1.24 \\
\hline Limited KT opportunities to certain disciplines & 3.35 & .97 \\
\hline Lack of communication about KT opportunities available & 3.35 & 1.17 \\
\hline Non-commercial culture of Universities & 3.28 & 1.30 \\
\hline $\begin{array}{l}\text { Differing strategic priorities for KT at different levels in the } \\
\text { institution }\end{array}$ & 3.25 & 1.13 \\
\hline Institutional risk aversion & 3.13 & 1.26 \\
\hline Unclear institutional/departmental KT processes & 3.13 & 1.18 \\
\hline Lack of flexibility in pricing structure & 3.10 & 1.19 \\
\hline Lack of encouragement to pursue KT at Department level & 3.05 & 1.24 \\
\hline $\begin{array}{l}\text { Lack of institutional track record of industry/commercial } \\
\text { experience }\end{array}$ & 3.05 & 1.20 \\
\hline Departmental risk aversion & 2.08 & 1.20 \\
\hline Lack of institutional reputation in specialist area & 2.68 & 1.18 \\
\hline Non-standardised processes for KT across institution & 1.24 \\
\hline Lack of investment in up-to-date equipment & 1.18 \\
\hline $\begin{array}{l}\text { KT perceived as less 'academic' and hence of less value than } \\
\text { teaching or research }\end{array}$ & 1.32 \\
\hline Lack of encouragement to pursue KT at Institutional level & & 1.35 \\
\hline
\end{tabular}


Table 3. Individual barriers impeding on academics' engagement in KT activities

\begin{tabular}{|l|r|r|}
\hline & Mean & \multicolumn{1}{l|}{ S.D. } \\
\hline Academic's time available to pursue KT is too fragmented & 4.05 & \multicolumn{1}{c|}{.88} \\
\hline Lack of academic's time to engage in KT & 3.90 & 1.00 \\
\hline Lack of reward/incentives for academic & 3.83 & 1.13 \\
\hline Mis-match of academic and commercial time-scales & 3.78 & 1.00 \\
\hline Academic's lack of control of funded research agenda & 3.35 & 1.07 \\
\hline Lack of academic's motivation to engage in KT & 3.33 & 1.18 \\
\hline $\begin{array}{l}\text { Academics personal preferences for UG/PG teaching/pure research vs. } \\
\text { KT }\end{array}$ & 3.33 & 1.12 \\
\hline Lack of academic's track record of industry/commercial experience & 3.20 & 1.27 \\
\hline Flexibility in approach to project required by client & 3.10 & 1.01 \\
\hline Mis-match in client needs and academic expertise & 3.05 & .90 \\
\hline Academic's lack of confidence - fear of unknown & 3.00 & 1.09 \\
\hline $\begin{array}{l}\text { Compromises academic's professionalism in other areas (e.g. teaching \& } \\
\text { research) }\end{array}$ & 2.98 & 1.33 \\
\hline Lack of academic's reputation in specialist area & 2.93 & 1.14 \\
\hline Academic's risk aversion & 2.90 & 1.08 \\
\hline Lack of availability of mentor support for academic & 2.88 & 1.09 \\
\hline Academic contract does not include KT & 2.83 & 1.39 \\
\hline Equity - Why should I if X doesn't? & 2.78 & 1.23 \\
\hline Academic reluctance to give expertise away & 2.20 & 1.20 \\
\hline Peer group pressure on academic to 'not engage' & 2.20 & 1.26 \\
\hline Engaging in KT has a negative impact on an academic's career & & \\
\hline
\end{tabular}

